\title{
Educação Superior e Educação Básica nos Institutos Federais: avaliação da verticalização de ensino com seus gestores
}

\author{
Giselle Rôças ${ }^{1}$ \\ Alexandre Maia do Bomfim ${ }^{2}$
}

\begin{abstract}
Resumo: Este artigo discute numa perspectiva analítica-crítica o encontro entre a Educação Básica e a Educação Superior proporcionado pela Lei 11.892 de 2008 para a implantação dos Institutos Federais. O debate é a verticalização do ensino que marcou e marca os institutos federais nos últimos anos, lhes concedendo uma peculiaridade não encontrada nas Universidades. A verticalização não é um elemento inovador dos institutos federais, tendo sido prevista e implementada nas últimas décadas do século XX nos Centros Federais de Educação Tecnológica, e já naquele momento, era prevista como algo muito além do que a ocorrência simultânea dos diferentes níveis e modalidades de ensino, preconizando o engajamento do docente que atuaria na sala de aula desde o ensino médio técnico até o ensino superior. $\mathrm{O}$ artigo apresenta como sessões (a) Breve apresentação da pesquisa; (b) Desafio imposto aos IF e à Rede: de nossa experiência e diálogo com nossos gestores até os gestores de outros Institutos e (c) De nossa compreensão de Instituto Unitário, passando pelo perigo da verticalização tacanha: que caminho seguir? (d) Horizontalidade na Verticalização e os desafios que permanecem: nossas considerações finais. Ao discorrer sobre a verticalização do ensino, destaca que não será qualquer verticalização que valerá a pena, para obter sucesso precisará observar especificidades, identidades e identificações.
\end{abstract}

Palavras-chave: Verticalização, Institutos Federais, Identidade.

\section{Introdução}

O avanço nas conquistas da classe trabalhadora, tanto nas relações de trabalho quanto no acesso à escola, não resulta, porém, mecanicamente da simples existência das contradições. Nem se trata de um avanço, apenas resultante do aproveitamento das brechas deixadas pela burguesia. Resulta, sobretudo, da apreensão adequada da natureza das contradições, de sua exploração política e, em suma, da organização da classe trabalhadora na luta por seus interesses (FRIGOTTO, 1993, p. 225). 
Há pouco tempo terminamos uma pesquisa intitulada "O Convívio da Educação Superior com a Educação Básica nos Institutos Federais: perderemos essa oportunidade?" (BOMFIM, 2017). Na verdade, um ensaio que pretendeu avaliar o encontro entre a Educação Básica (EB) e a Educação Superior (ES) proporcionado pela Lei 11.892 de 2008 para a implantação dos Institutos Federais (IF) (BRASIL, 2008). Esse estudo serviu para retomarmos elementos da própria lei, seus objetivos, bem como os posicionamentos iniciais de desconfiança e alguns até contrários aos IF. Posicionamentos que problematizaram a verticalização do ensino e demonstraram receio que houvesse precarização da EB e inclusive da ES dentro dos IF. Não obstante, sabíamos que tínhamos algo novo e importante nas mãos, considerando à organização da educação no Brasil, porque a verticalização do ensino que marcou e marca os IF nos últimos anos lhes concede uma peculiaridade não encontrada nas Universidades. Isso tem que ser pesquisado permanentemente, sempre reavaliado e sempre revistos seus encaminhamentos. Quevedo (2016, p. 9) afirma que a verticalização não deve ser compreendida a partir do olhar de um segmento (docente, técnico e/ou discente) ou mesmo nível e modalidade (ensino médio, superior, EJA, entre outros), pois "a verticalização só é possível embasada em uma proposta institucional, esta se torna uma prática a ser construída coletivamente".

Em sua concepção primeira, Pacheco (2011) assume que a verticalização atuaria como proposta pedagógica que compreende a educação básica, o ensino técnico profissionalizante e o ensino superior (hoje com as licenciaturas, bacharelados, lato e stricto sensu), devendo ser um elemento constituinte do desenho curricular, assumindo a transversalidade da tecnologia, pois está presente na tríade ensino-pesquisa-extensão. Pacheco reforça que a verticalização atuaria como uma força organizadora do currículo dos cursos e da proposta pedagógica dos campi, permitindo ao aluno de um instituto federal traçar seu itinerário formativo desde a sua chegada no ensino médio técnico ao doutorado, caso assim lhe aprouvesse.

Retoma-se aqui a compreensão de que a verticalização não é um elemento inovador dos institutos federais, tendo sido premeditada e implementada nos CEFETs, e já naquele momento, era prevista como algo muito além do que a ocorrência simultânea dos diferentes níveis e modalidades de ensino, preconizando o engajamento do docente 
que atuaria na sala de aula desde o ensino médio técnico (EMT) até o ensino superior usando os argumentos (FERNANDES, 2013), conhecimentos e experiências adquiridas no contexto da sua pesquisa, possibilitando aplicar na prática algo preconizado e perseguido pelas universidades: atuar de forma igualitária no tripé ensino-pesquisaextensão.

Para aquela primeira pesquisa, que consideramos panorâmica, contamos com alguns depoimentos de discentes, servidores docentes e servidores técnicosadministrativos do IFRJ, nosso local de trabalho. O relatório dessa pesquisa nos permitiu algumas conclusões e um posicionamento, que: 1) os IF alcançaram expressivamente a Educação Superior Tecnológica e a tarefa da Formação de Professores da graduação à pós-graduação nesses quase dez anos; 2) os IF mantiveram o convívio com o Ensino Médio-Técnico (conforme a Lei), mas não foram encontradas ações diferenciadas e significativas que estabelecessem entrosamento entre a EB e ES; 3) os agentes (servidores e docentes) envolvidos com a verticalização serão indispensáveis ao seu desenvolvimento, mas os gestores possuem um protagonismo a ser avaliado; 4) no fim das contas, nos colocamos politicamente favoráveis à verticalização de ensino, porque seria possível uma relação simbiótica (benéfica para os dois) entre a Educação Básica e a Educação Superior", através de uma Educação Científica do Ensino Médio até a pós-graduação stricto sensu dentro de uma mesma Instituição. Considerando essas inferências que alcançamos, nossa hipótese de trabalho é que dentre os sujeitos participantes do Projeto dos IF, especialmente para verticalização de ensino, os gestores seriam uns dos mais importantes, mas exatamente eles são os que podem mais obstaculizar seu desenvolvimento. Ou seja, esse é o propósito deste artigo: avaliar a verticalização do ensino com e a partir dos gestores, ainda que não desconsideremos a participação dos docentes, discentes e demais servidores.

De maneira geral, os gestores nos IF estão em seus cargos por força de uma eleição e, mesmo para os casos de indicação (cargos pró-tempore), são representantes de grupos dentro da instituição, provavelmente os hegemônicos. E, embora alguns gestores (gerais) tenham sido entrevistados, foram os ligados ao ensino que focamos neste momento, porque estão numa posição favorável para ler o que acontece entre os 
professores, as equipes, os alunos e os demais servidores em relação à estrutura e em relação à própria comunidade do entorno, etc. Essa é nossa justificativa para começar uma reflexão com eles - os dirigentes -, mas que se pretende alcançar e aprofundar o debate com os demais atores sociais, acompanhando uma tendência que assumem os IF como cenário de pesquisa buscando a compreensão da verticalização a partir de olhares e vivências dos seus campi (FERNANDES, 2013; BOAVENTURA, 2016; PADILHA e FILHO, 2016; OLIVEIRA, 2016).

\section{Breve apresentação de nossa pesquisa}

Compreendemos que a reflexão que nos propomos a fazer aqui não ficará restrita à pesquisa que fizemos com os gestores, porém, também não deve prescindir dela. Não fica de forma estrita porque é uma reflexão que pressupõe elementos teóricos políticos anteriores, tais como a Lei 11.892, de 29 de dezembro de 2008, (implementando os IF), passando pelas críticas, por autores de referência, incluindo nosso posicionamento quanto à possibilidade da verticalização do ensino. Mas, também não poderiamos abrir mão de uma mínima investigação, porque pressupõe uma avaliação, precisa do diálogo com outros interlocutores, precisa colocar à prova uma proposta de compreensão de educação e considerar diferentes realidades.

Destarte, fomos aos gestores (preferencialmente ligados a ensino), através da Rede Técnica Federal, para que nos respondessem quatro perguntas abertas: 1) De maneira geral, como está o convívio entre a Educação Superior (ES) e a Educação Básica (EB) em seu IF? (Considere pontos forte e pontos fracos); 2) Do seu ponto de vista, quais são perspectivas para esse convívio dentro dos IF? 3) Em sua opinião, o que os gestores deveriam fazer em relação a esse convívio, considerando um futuro imediato e de médio prazo? 4) Quem mais de sua Instituição (preferencialmente Pró-reitor(a) ou Diretor(a) de Ensino) indicaria para prosseguirmos com essa pesquisa? (Pode, inclusive, contatá-lo?). 
A análise dessas respostas se dará ao longo do artigo porém valem três aperitivos a seguir, três "nuvens de palavras" para cada uma das três primeiras perguntas do pequeno questionário.

\section{Imagem 1: Como os gestores veem o convívio entre ensino superior e a educação básica.}

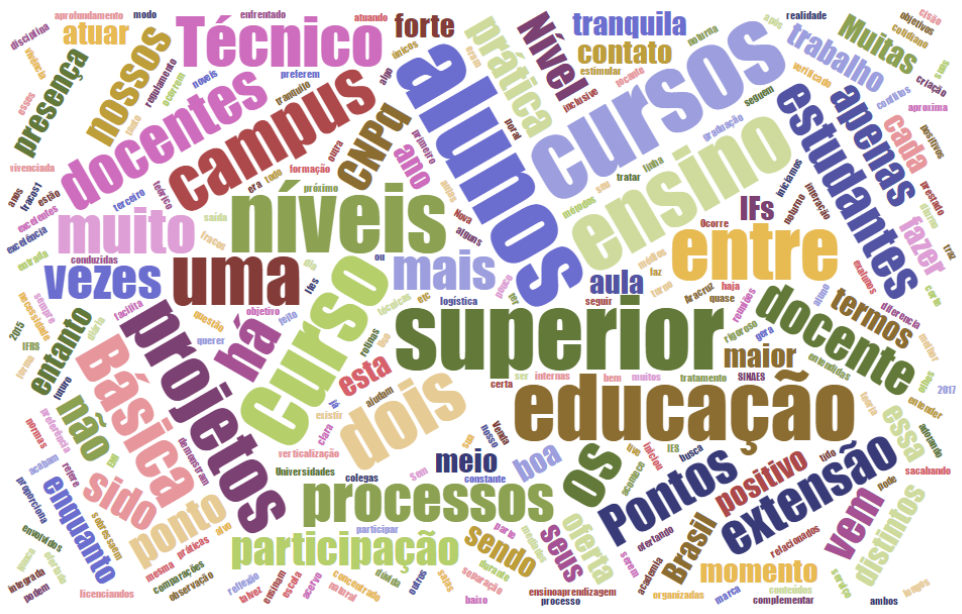

Fonte: elaboração própria, a partir das entrevistas.

Em se tratando de um aperitivo da análise, não convém especular excessivamente sobre os quadros (acima e os que vem a seguir), dessa forma fiquemos com as palavras que expressivamente se destacaram. Nesse primeiro, destacaram-se as palavras: "alunos”, “cursos" (e "curso" no singular), "superior” e "educação". E depois: “projetos", "técnico", “processos”, “campus”, seguidos por "Básica”, “docentes” (com “docente" no singular), "extensão", entre outros ${ }^{4}$. Com pouco a inferir até então, vale

\footnotetext{
Essas "nuvens de palavras" foram preparadas com antecedência. Procuramos constituí-las com mais substantivos e verbos, diminuindo elementos de ligação. As "nuvens de palavras" (ou "word cloud") podem ser confeccionadas em inúmeros sites, as que fizemos se deram nesse endereço: <https://www.jasondavies.com/wordcloud/>. Vale dizer que as "nuvens de palavras" servem apenas para obter determinado cenário ou panorama, ligando-se às questões estéticas, e podendo ser vistas até mesmo como uma forma de "epígrafe". No entanto, seu uso indiscriminado em artigos científicos nem sempre tem ajudado. As nuvens de palavras servem para apresentar a frequência proporcional com que as palavras aparecem no texto. A análise se limitou, neste momento, a isso.

Talvez um leitor muito distante dessa temática não perceba que palavras como "técnico", "básica" ligam-se à ideia de Ensino Médio "Técnico" e a de Educação "Básica", como "superior" à Educação "Superior", porque foi com esse contorno que ocorreram as entrevistas, mas isso ficará mais
} 
uma problematização. A visualização de que a palavra "superior" está com mais destaque do que "técnico" e "básica".

Em destaque menor, mas não menos intrigante, surgem as palavras " $\mathrm{CNPq}$ ", "projeto" e "extensão". Ainda que possamos intuir que "projeto" e "CNPq" estejam atrelados à pesquisa, o termo por si só, não comparece nas falas dos entrevistados, sendo igualmente surpreendente a ausência da palavra "CAPES, contrapondo ao "CNPq", já que alguns IF possuem mestrados e doutorados. Será que procede a desconfiança daqueles que no início da implementação do IF se preocupavam que a Educação Superior prevalecesse em relação à Básica $^{5}$ ?

Vamos agora à segunda imagem, composta, tal qual a anterior, com base nas palavras presentes nas respostas dos dirigentes que aceitaram participar dessa pesquisa.

Imagem 2: Imagem das palavras relacionadas às expectativas dos gestores sobre ensino superior e a educação básica.

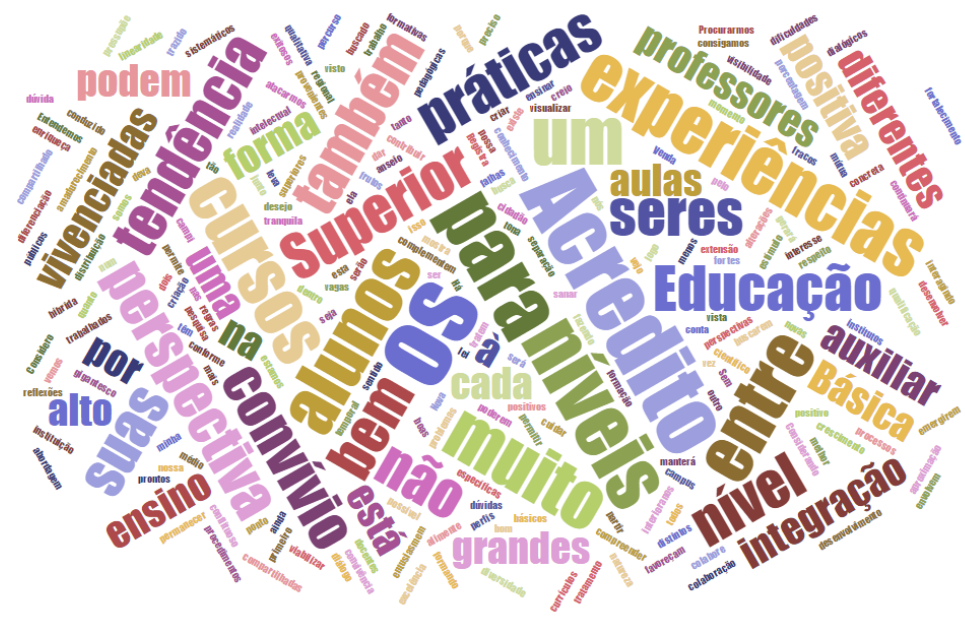

claro com a utilização mais direta dos depoimentos, à frente. Vale dizer que trataremos cada termo desse, independente de vir no plural, simplesmente como "palavras" em respeito a ideia de "nuvens de palavras". Também estaremos considerando mais os substantivos e verbos, os elementos de ligação (pronomes, advérbios, preposições) que persistiram nas nuvens não fazem parte de nosso escopo.

Essa, por exemplo, era a preocupação de Frigotto, Ciavatta e Ramos em 2005: [Será que] (...) com o reconhecimento dos Centros Federais de Educação Tecnológica (CEFETs) como instituições de ensino superior, a prioridade tenderá a ser conferida à oferta da educação superior em detrimento do nível médio (...) [?]. (FRIGOTTO; CIAVATTA; RAMOS, 2005, p. 1097). 
Fonte: elaboração própria, a partir das entrevistas.

É pertinente, e até certo ponto curioso que, se tratando da expectativa dos gestores para o convívio da ES e EB, se destaque a palavra "acredito". Esses gestores demonstraram imediatamente que acreditam na verticalização de ensino. Contudo, poderemos dizer que a palavra "acredito", embora indique uma positividade, não é contrabalançada por um sentido mais concreto que outras palavras poderiam remeter, como por exemplo, "ações", "políticas", e "encaminhamentos". O surgimento do "acredito" numa nuvem de palavras elaborada a partir de um questionamento que envolve política pública de educação é também um incomodo, pois em certa medida remete a crença individual do quanto cada um embarca ou não na proposta de verticalização do ensino preconizada pela lei de criação dos IF, sendo temeroso o surgimento dela ao considerar que os respondentes estão envolvidos na gestão. As palavras "experiências", "práticas", "tendência" e "vivenciadas" também tem significativo destaque. Dessa forma, pareceu haver alguma consideração pelo passado ou mesmo presente, na tentativa de envolver os níveis de ensino. Considerar a experiência no processamento do futuro, pelos gestores, é indício importante de materialização de projetos. "Superior" voltou a ter mais destaque do que "Básica". De maneira geral, pode-se perceber que são palavras não pejorativas. Assim, vamos à terceira nuvem.

Imagem 3: "O que fazer?" - O que os gestores devem fazer em relação a esse convívio da sobre ensino superior e a educação básica. 


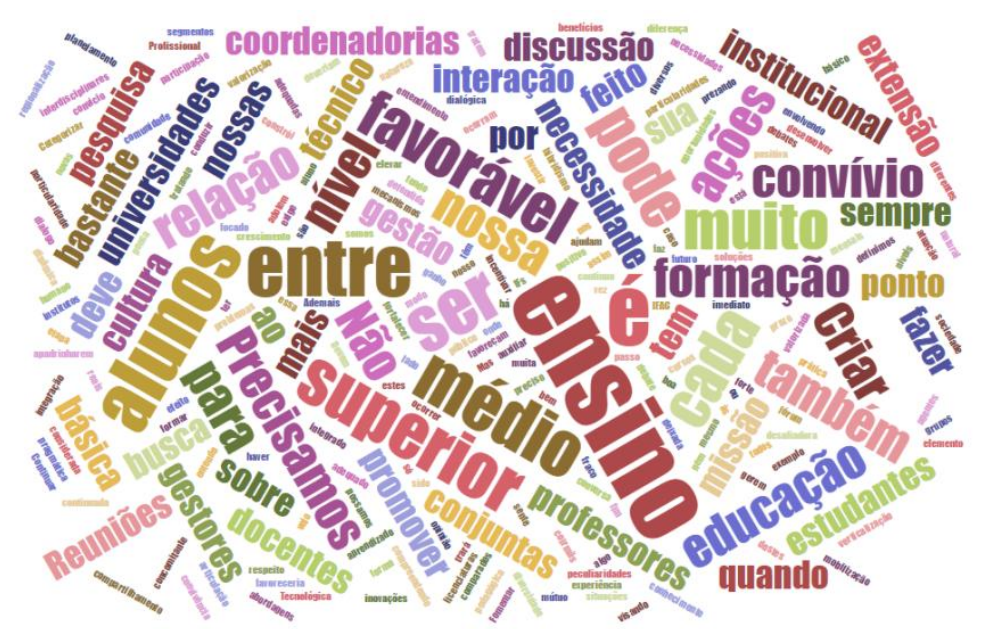

Fonte: elaboração própria, a partir das entrevistas.

Excetuando-se a palavra "ensino" com mais destaque (e com a qual não temos como inferir muito), aparecem na imagem 3 com boa expressão: "alunos", "favorável", "superior" e "médio". "Básica" voltou a vir pequena, mas considerando que "médio" se destacou, podemos arriscar em dizer que em relação à questão 3 (intencionada a apreender as ações que os gestores poderiam implementar) parece que o ensino "médio" está vindo bem representado na imagem. Em tamanho menor, mas considerando os pressupostos previstos pela política pública que instituiu os IF, não podemos deixar sem destaque o surgimento das palavras "pesquisa", "extensão" e "cultura". De qualquer forma, no prosseguimento deste artigo vamos dialogando mais diretamente com nossos entrevistados e demais interlocutores. Vale descrever a seguir o que temos na mão para análise.

Temos entrevistas de treze gestores que constituem nosso grupo de trabalho, de sete Institutos Federais diferentes (IF-Goiano, IF-Baiano, IFES, IFAC, IFPB, IFCE, IFB, IFRS), que complementarão (e também confrontarão) a visão alcançada e a experiência que possuímos em nosso instituto (IFRJ). Nenhum dos gestores terá a identidade revelada. Desses treze, sete são diretores de ensino, um é pró-reitor de extensão, dois são pró-reitores de ensino e três são diretores-gerais, os quais passarão a ser designados apenas como gestores $(\mathrm{G} 1, \mathrm{G} 2, \ldots)$. 


\section{Desafio imposto aos IF e à Rede: de nossa experiência e diálogo com nossos gestores até os gestores de outros Institutos}

Antes de prosseguirmos, vale dar maior precisão para nosso pressuposto de trabalho (que apresentamos acima). Há dois pressupostos iniciais: (1) os dirigentes são peças chaves desse processo de verticalização e por isso lhes demos foco; (2) são agentes importantes para desenvolver ou obstaculizar o processo. E o elemento que queremos confirmar, que requererá nossa atenção para apreender e para não construir falsamente a hipótese (3) de que mesmo quando os gestores "acreditam" na verticalização não implementam ou não participam de ações (da macro ou micropolítica) no sentido de fortalecê-la. Essa é nossa desconfiança.

A verticalização é uma novidade para a maior parte dos dirigentes e docentes, embora seja realidade na rede desde os CEFETs que nuclearam a rede atual dos IF, mas não podemos nos esquecer do processo de Cefetização que as escolas técnicas federais sofreram em meados dos anos 90 (CAMPELLO, 2007). Para Ferreti (2011)

Quanto aos caminhos próprios percorridos pelo CEFET-SP, verificouse que o processo de "cefetização"/implementação das reformas gerou a produção de um Projeto Pedagógico em 1997/1998 que, ao mesmo tempo, buscou contemplar as recomendações do MEC e, de outro, introduzir uma leitura institucional própria que resultou em encaminhamento marcado pela ambiguidade. [...] caracterizam o processo de implantação tanto do proposto pelos decretos n. 2.208/97 e 5.154/04, quanto da verticalização experimentada pela instituição. Estiveram em jogo, sob esse aspecto, os interesses ideológicos dos professores, expressos na sua concepção do que seria uma boa educação técnica, seus interesses pessoais, na medida em que a educação então oferecida era consistente com sua identidade profissional, assim como seus interesses criados, dado que a transformação da ETFSP em CEFET-SP lhes possibilitaria, em tese, construir uma carreira que não se encerraria no âmbito de um curso técnico de nível médio (FERRETI, 2011, p. 793, grifo nosso).

"Cefetizamos" as escolas técnicas federais e, cerca de 10 anos depois, "ifetizamos" os CEFETs, com a expansão da Rede Federal em tempo recorde e capilaridade intensa, e nesse ínterim queremos apresentar uma identidade consolidada, apesar de termos ampliado o quadro de servidores em quantitativos exponenciais, sem ter a devida acolhida e preparo de todos, em especial do docente que deve atuar em todos os níveis e modalidade de ensino. Rocha e Léda (2013) chamam a atenção para 
essa questão, pois o professor de Ensino Básico, Técnico e Tecnológico (EBTT), atua por vezes na EB, ES e PG, além do EJA e demais cursos de capacitação, com exigências de metodologias, transposições, avaliações e linguagens totalmente distintas. Tal situação é descrita por alguns gestores que participaram da pesquisa, ao afirmar que

[...] talvez o ponto que precisamos trabalhar é o interesse dos docentes em migrarem para o ensino superior somente. Outra questão é querer tratar a educação básica como ensino superior, com os mesmos métodos, técnicas, avaliações, etc. (G3).

No tocante aos docentes, alguns demonstram clara preferência em trabalhar apenas com os cursos superiores enquanto outros preferem o nível médio (G4).

Dificuldade dos docentes em estabelecer o planejamento, a transposição didática e a linha de corte dos conteúdos e objetivos levando em consideração as peculiaridades de cada nível. Muitas vezes ensinam a mesma aula no curso técnico e no curso superior (G6).

A dificuldade inicial no desenvolvimento da compreensão do docente recém-chegado de que deverá atuar nos dois níveis; Dificuldades no lidar no desenvolvimento das equipes pedagógicas para atuar nos dois níveis (G7).

A cada nova política pública de "ajuste" da educação profissional e tecnológica (EPT), novos objetivos são desenhados, novas ações e atuações são previstas, mas o perfil do "novo" servidor público não é pensado, em especial os docentes. Ainda durante as ETFs o professor sabia para qual instituição estava se candidatando. Identificava com alguma facilidade o perfil dos futuros alunos, sabia qual era o objetivo da instituição, compreendia (em alguma medida) o que esperavam dele como docente em uma sala de aula (que pressupunha formar um aluno dentro do arcabouço da EPT). Ao virarmos CEFET, já se fez necessário um novo entendimento. Com a oferta das graduações, primeiramente pautadas nas áreas mais tecnológicas, o perfil havia começado a mudar, mas antes mesmo de entendermos quem seriam esses novos professores, já tínhamos virado IF! Fernandes define bem essa situação ao afirmar que

A verticalização iniciada no modelo CEFET, que ainda hoje mantém ativa muitas de suas determinações, não consistia tão somente na justaposição de graus de formação e níveis de ensino, mas pretendia favorecer um intercâmbio de professores que atuavam num mesmo 
departamento, porém ministrando aulas para os ensinos médio e superior (FERNANDES, 2013, p. 29).

O olhar dos autores sobre a possibilidade de problemas em relação ao convívio da EB e ES nos IF fundamenta-se nas suas próprias experiências e observações, de seu próprio instituto, mas também de conversas com outros colegas de outros institutos nas visitas que fazem vez por outra. E ainda que os gestores aqui entrevistados indiquem a ausência de dificuldades nessa convivência, percebemos em suas falas elementos de que o encontro entre os níveis pode ser muito incipiente, (especialmente pelo fato de que as turmas de EMT estejam essencialmente nos turnos matutinos e vespertinos, enquanto a graduação é noturna). Esse efeito "Feitiço de Áquila" médio encontrem, ainda que por instantes, os alunos da graduação, mas com uma convivência temporal bastante limitada. Podemos observar essa realidade no depoimento de alguns gestores.

A convivência está tranquila. Até porque o campus $[\mathrm{x}]$ iniciou a verticalização do ensino ofertando o primeiro curso superior no ano de 2015. Agora, em 2017, iniciamos nosso terceiro curso de graduação. O ensino médio acontece durante o dia e quase todo o superior está concentrado no turno noturno. Ocorre meio que uma separação temporal entre os diferentes níveis de ensino. Isso facilita um pouco a organização e a logística dos alunos no campus já que é feito, por exemplo, um controle rigoroso de entrada e saída dos alunos do ensino médio enquanto que para o superior não há esse controle (G4).

O campus oferta apenas um curso superior de oferta noturna. Os cursos da educação básica ocorrem no diurno. O convívio é tranquilo (G5).

Tranquila. A Educação Superior e subsequentes são cursos noturnos, e o EMI é matutino/vespertino. Nunca houve nenhuma dificuldade nas atividades condutas $(G 9)$.

Na experiência que tive, os alunos da Educação Superior tinham contato apenas com os estudantes da Educação Básica do Curso Técnico de Nivel Médio Integrado na Modalidade PROEJA. Sendo assim, todos os estudantes eram mais velhos (G10).

\footnotetext{
6 Referência ao filme americano "Feitiço de Áquila" (Ladyhawke, 1985), em que a protagonista "Isabeau" vivida por Michelle Pfeiffer não conseguia encontrar plenamente o seu amado Navarre, vivido por Rutger Hauer, a não ser por poucos segundo no momento do crepúsculo, por conta de uma maldição, que a aprisionava ao dia, enquanto ele era aprisionado à noite.
} 
Até o presente momento não há nenhum tipo de conflito. Acreditamos que o fato da Educação Superior, até o presente momento, ser ofertada apenas no período noturno, oposto ao da Educação Básica, facilita a boa convivência. Não identificamos pontos fracos nessa relação de Cursos/Modalidades (G13).

As passagens acima são emblemáticas para analisarmos. Todas demonstram "tranquilidade" para o encontro entre EB e ES. A tranquilidade se dá porque os horários são distintos (ES costuma ser noturna e EB ser diurna), ou seja, os estudantes de diferentes níveis praticamente não se encontram. Os gestores "até o presente momento [não encontraram] nenhum tipo de conflito" (G13), o que "facilita um pouco a organização e logística dos alunos" (G4). Ou seja, esses gestores não se opõem ao convívio (mesmo porque é muito pequeno) entre os graduandos e secundaristas; não há significativamente nada visível à verticalização. Até aqui, parece que há único elemento de convergência entre os estudantes é a utilização da mesma estrutura física dos Institutos, mas em períodos diferentes. Quer dizer, graduandos e secundaristas fazem uso do mesmo "espaço", mas não do mesmo "tempo". Isso até facilitaria a "boa convivência" (G13).

Por não haver problemas e/ou reclamações (segundo esses gestores) é que o convívio entre EB e ES está tranquilo e saudável? Os problemas existem, mas não estão sendo pensados em conjunto, sistêmica e internamente em cada Instituto, inclusive não estão sendo pensados dentro da compreensão de "Rede". Continuemos sobre os gestores.

Alguns gestores têm buscado formas para contornar a insatisfação de alguns docentes, assim como o receio e/ou pouco preparo. A chegada dos IF e a proposta da verticalização de forma mais efetiva trouxeram também novas funções aos docentes. Oliveira (2016) identificou, em sua pesquisa, as dificuldades dos docentes para lidar com a verticalização, face ao baixo ou nenhum suporte prático (infraestrutura e recurso humano), face à integração dos diferentes níveis e modalidades de ensino, quanto, por exemplo, à estruturação de currículos diferenciados. Em resposta à enquete que realizamos, alguns gestores apontaram que a relação entre pesquisa e extensão poderiam ser os elementos principais para adesão do corpo docente. 
O envolvimento dos alunos dos diferentes níveis em projetos de pesquisa e extensão também é positivo, o enriquecimento do acervo bibliográfico e laboratórios também (G5)

Possibilidade de desenvolvimento de pesquisa e extensão com a participação de alunos dos dois níveis $(G 7)$

Um dos exemplos a ser citado, que traz com muito sucesso essa aproximação, é a participação de discentes de diferentes níveis em projetos de ensino, de pesquisa, de extensão e projetos indissociáveis (G12)

Essa aproximação do ensino com a pesquisa e a extensão reforçam a ideia primeira dos IF defendida por Pacheco (2011), ainda que ela ocorra de forma mais ampla do que a assunção inicial do eixo tecnológico como elemento transversal para o desenho das matrizes curriculares. A verticalização pressuposta pelo autor e um dos idealizadores dos IF, preconiza que um aluno ao entrar no IF no ensino médio se percebe capaz de chegar até o ensino superior. E essa possibilidade se percebe concretizada na fala de alguns gestores que participaram dessa pesquisa. De tal forma que, minimamente, a verticalização tem atendido alguns dos seus objetivos primários, mas que se faz necessário investigar os nós e investir em soluções efetivas e duradouras, possivelmente, começando pelo perfil dos docentes nos editais de seleção. Nem todos precisam/conseguem ser flexíveis o suficiente para atuar em todos os níveis de ensino de um IF.

Além de refletirmos mais sobre a verticalização, vale problematizar sua situação em termos de rede, pois ainda que aconteça em alguns institutos, não será suficiente para atingir toda a rede, já que nasceu por força de uma Lei federal e sempre pretendeu esse grande alcance. Constituímos a Rede Federal de Educação Profissional, Científica e Tecnológica, assim sendo, se temos a capilaridade nacional com o funcionamento inicial de 644 campi, por que não conseguimos nos conhecer? Por que não há troca de informações entre os IF? Por que o que se discute no CONIF, não é capilarizado até a sala de professores e a sala de aula? Por que a voz dos docentes, técnicos administrativos e discentes não é ouvida e replicada em grupos de trabalho nacionais, objetivando a consolidação da rede? Ou fazemos algo para melhorar nossas ações e indicadores ou sofreremos uma nova ação (de algum governo), por força de uma política pública (idiossincrática), tal qual já ocorreu nas duas últimas vezes (pela 
cefetização e ifetização), pois estamos completando 10 anos de IF e o nosso resultado coletivo não responde diretamente ao investimento realizado.

Voltando para mais alguns depoimentos, percebemos a todo instante que os gestores percebem a verticalização como algo positivo do ponto de vista do discente, mas as falas pouco tangenciam a atuação dos técnicos administrativos e docentes que perdurarão, ou não, na instituição.

O convívio é interessante pois muitos ex-alunos dos cursos técnicos acabam por fazer os cursos superiores, acabando por permanecer na Instituição por longos anos. Isso favorece a criação de uma identidade de nossos alunos que se respeitam mutualmente (G2)

A possibilidade de visualização dos alunos com baixo rendimento em uma perspectiva de futuro diferente e possível. Um aluno de ensino médio tem o curso superior mais próximo dos seus olhos, na convivência diária, isso pode estimular e ampliar seu desejo de seguir seus estudos (G6)

A presença dos dois niveis em um campus favorece o conhecimento dos discentes do perfil dos cursos superiores e vice-versa. Por vezes temos alunos que fazem um curso técnico e seguem no ensino superior no IF e também há aqueles que, após o contato com o curso técnico o faz para complementar a sua formação (G7).

Quando perguntamos aos gestores acerca das perspectivas deles sobre esse convívio da EB e ES nos IF, a maioria aposta que não haverá problemas. Fato que os que apontaram essa visão positiva são exatamente aqueles institutos que fizeram a separação dos turnos de tal forma que a convivência é praticamente inexistente. Ainda assim, acreditam que tal separação favorece a criação de medidas distintas, conforme assinalado pelo gestor 4:

A separação temporal que estamos fazendo nos permite cuidar de cada um dos níveis conforme suas regras específicas (G4)

Os gestores também concordam, em sua maioria, que do ponto de vista dos alunos, esse convívio é profícuo, pois permite que eles se percebam também pertencentes ao ensino superior, conferindo a eles esse sonho de completar seus estudos. $\mathrm{O}$ respeito a diversidade também foi um ponto apresentado como fruto positivo dessa convivência mútua.

Acredito que a convivência entre públicos de perfis distintos colabore com o trabalho sobre respeito à diversidade (G10) 
Segundo alguns poucos gestores que olham para essa categoria, a verticalização favoreceria(rá) o repensar da prática pedagógica dos professores, pois ao ministrarem aulas em mais de um nível de ensino, em especial EMT e licenciaturas, eles podem refletir sobre essa prática e utilizar tal reflexão nos momentos em que estão formando novos professores durante as aulas de licenciatura. Essa autorreflexão, atrelada a associação da pesquisa e extensão, ampliam positivamente os resultados advindos da verticalização do ensino.

Acredito que são boas e que a tendência é que as experiências vivenciadas nos cursos da educação básica podem auxiliar os professores na busca da excelência de suas aulas junto aos cursos superiores, bem como, as experiências vivenciadas nos cursos de ensino superior podem auxiliar os professores a buscarem alterações em suas aulas para poderem sanar dúvidas ou falhas de conhecimento dos alunos provenientes dos cursos básicos (G2)

A partir do amadurecimento de todos é possível visualizar uma integração entre os dois níveis, de forma que um alimente o outro, tanto nas práticas pedagógicas, como no "que ensinar" (G6)

Ademais, a nossa natureza pragmática favoreceria as possibilidades de inovações no ensino, pesquisa e extensão. A nossa experiência na educação básica também é favorável em nossas licenciaturas. Um docente que tem a prática pedagógica no ensino médio concomitante a sua atuação como docente é elemento favorável na formação de professores $(G 7)$

Apesar da verticalização já ocorrer há quase 20 anos, desde os CEFETs, conforme já apontado no texto. Os autores percebem que essa perspectiva dos gestores sobre a autorreflexão não ocorre de forma espontânea, ao menos não com o entusiasmo esperado, além disso, pouco ou nada é abordado do ponto de vista dos técnicos administrativos que também vivenciam a verticalização, fato corroborado por outros estudos (CAMPELO, 2007; FERNANDES 2013; BOAVENTURA, 2016; OLIVEIRA, 2016).

Sobre as respostas dos gestores, percebemos que a maioria, ainda que não criem obstáculos evidentes à verticalização, segregam os níveis de EB e ES para turnos distintos. Não cremos que seja uma prática pensada e orquestrada, mas sim uma 
resposta padrão de repetição ao modelo que estamos acostumados, levando para o turno da noite o aluno mais velho, que busca a complementação da sua formação.

Entretanto, em nossa pesquisa, ao menos dois gestores parecem creditar na verticalização algo mais concreto, buscando discutir e implementar ações no sentido de fortalecê-la. No primeiro caso, o gestor reconhece nossa característica híbrida, mesclada, e aposta nessa compreensão para encontrarmos soluções internas. O segundo aposta na necessidade de reconhecimento das boas práticas e na compreensão desses processos compartilhados.

A minha perspectiva é de que esse convívio será tão melhor quanto nós consigamos compreender a nossa natureza híbrida. Procurarmos desenvolver processos dialógicos que favoreçam atacarmos os nossos prontos fracos e ofortalecimento dos pontos fortes $(G 7)$

A instituição tem buscado viabilizar e dar visibilidade aos procedimentos exitosos que tratem de uma abordagem qualitativa no percurso compartilhado entre a Educação Básica e Educação Superior. Entendemos que é preciso novas iniciativas e que as reflexões e as práticas que emergirem do diálogo e problematização sistemáticos, enriqueça os currículos, as práticas compartilhadas e as experiências formativas. Sem dúvida, as iniciativas de aproximação e colaboração mútua têm trazido à tona a perspectiva de problematização que envolvem as experiências de verticalização e a linearidade que pressupõe o desenvolvimento científico (G12)

$\mathrm{Na}$ terceira questão, convidamos os gestores a refletir sobre quais seriam as suas ações (a curto e médio prazo) em relação ao convívio do EB e ES. Ainda que alguns poucos compreendam que não há necessidade de executar tarefa alguma, considerando que não há relatos de problemas, a maior parte dos gestores aposta no diálogo conjunto, na efetivação de fóruns de discussão, no reconhecimento da identidade dos IF e nas particularidades de cada nível e modalidade de ensino, apostando também que com a execução efetiva do tripé ensino-pesquisa-extensão seria o caminho à qualificação. De forma que, entre um Instituto e uma Universidade, a existência e a convivência com a EB seja nosso maior e melhor diferencial. Nessa pergunta, ainda que alguns gestores ainda foquem muito no aluno, já houve de forma mais presente o surgimento da relação do docente-gestor-discente.

Outro apontamento que apareceu de forma positiva, foi o de mostrar a estreita relação entre a EB e as licenciaturas. Esse encontro apontado pelos gestores merece 
destaque, pois a verticalização pressuporia outros cursos, especialmente os tecnológicos. Será que o convívio entre a EB e as licenciaturas se mostrou mais significativo à verticalização? Como por exemplo, num lugar fora do espectro das licenciaturas, ocorre no Campus Rio de Janeiro do IFRJ, um curso de EMT em Biotecnologia, com um bacharelado em Ciências Biológicas com Habilitação em Biotecnologia, com um mestrado e doutorado em Bioquímica e Biologia Molecular - um exemplo de verticalização, que garante a convivência dos alunos em todos os turnos, para as atividades de ensino-pesquisa-extensão, como também a atuação dos docentes em todos os níveis e modalidades. A verticalização aqui é possível e real por conta da existência de uma temática transversal, que atravessa e está presente a todo instante na matriz, nas discussões, nas ações, no estabelecimento de um perfil de docente a ser selecionado, na infraestrutura necessária, na convivência efetiva dos alunos e assim por diante. Conforme apontado pelo gestor 12.

Criar situações de compartilhamento e valorização de cada etapa do conhecimento, promover a formação continuada dos docentes, visando a Educação Profissional e Tecnológica, a verticalização do ensino, a discussão e mobilização pelas abordagens interdisciplinares. E, por fim, um planejamento de ações conjuntas envolvendo os diferentes segmentos, e que tratem da relação institucional entre a educação básica e superior, da regionalização do ensino básico e superior e de novas oportunidades de interação (G12)

Não seria o aproveitamento dos recursos humanos e de infraestrutura mais eficientes e efetivos do que a proposta de adoção de alunos do ES em relação aos alunos do EMT? Conforme apontado por um dos gestores entrevistados:

[...] é preciso incentivar que estes "adotem" os estudantes de nível médio. $O$ ensino médio integrado ao ensino técnico exige bastante dos alunos. Se os alunos do ensino superior apadrinharem os alunos do ensino médio pode haver um efeito muito positivo em ganho de aprendizado. É isso precisamos fortalecer cada vez mais (G4)

Esse "apadrinhamento" não pressuporia que os alunos da EB estejam numa situação "inferior", em que necessitaria de uma condução pelos alunos mais velhos e experientes? Ou foi somente força de expressão, no sentido de que pudesse haver expectativa de que os licenciandos "adotassem" secundaristas mais no sentido de garantir um estágio docente e/ou de contribuir à formação deles (por algumas vezes 
deficitária) semelhante a monitores? Independentemente, o fato é que "idealmente" os gestores apontam que seria muito bem-vindo o encontro entre a Educação Básica e a Graduação da Licenciaturas, mas, o fato é que a materialização da verticalização ou encaminhamentos para isso praticamente não ocorrem.

\section{De nossa compreensão de Instituto Unitário, passando pelo perigo da verticalização tacanha: que caminho seguir?}

Desde o início deste trabalho, temos demonstrado o quanto somos favoráveis à verticalização do ensino, boa parte disso porque vemos o quanto essa proposta poderia ir ao encontro (ou ao menos se aproximar) do que entendemos como sendo uma Escola Unitária e do Trabalho, próximo do que Saviani sempre defendeu:

(...) é de fundamental importância que se pense a educação nacional a nível de sistema, isto é, como um conjunto cujas partes devem ser intencionalmente articuladas num todo unitário e coerente. Nesse contexto não há como evitar o tema da escola unitária (SAVIANI apud MACHADO, 1989, p. 7).

A verticalização de ensino dentro de uma escola, que considera (e muito) o saber advindo dos trabalhadores, que considera a educação tecnológica associada à propedêutica, não seria uma oportunidade na direção da escola unitária? Na direção de uma escola que considerasse a omnilateralidade do humano. Para esclarecer ainda mais nosso posicionamento, vale a citação a seguir:

\footnotetext{
Em linhas gerais, a concepção marxista de educação foi gradativamente se configurando e assumindo os seguintes princípios: eliminação do trabalho das crianças nas fábricas; associação entre educação e produção material; educação politécnica que leva à formação do homem omnilateral, que abrange três aspectos: mental, físico e técnico, adequado à idade das crianças, jovens e adultos; inseparabilidade da educação e da política; articulação entre o tempo livre e o tempo de trabalho, isto é, o trabalho, o estudo e o lazer (LOMBARDI, 2011, p. 224).
}

Associando essa compreensão de escola, expandindo-a ao que Saviani disse acima para "nível de sistema", para um "todo unitário e coerente", não seriam os IF um dos melhores lugares para testar essa proposta de educação, dentro do cenário da educação brasileira? 
Ainda que de maneira geral, nossos principais referenciais teóricos (Saviani, Grasmci, Kuenzer, Frigotto, Manacorda, Nosella, Machado, etc.), quando estão se referindo às compreensões de Escola Unitária, Politécnica e/ou Integral, tenham como foco principal a Educação Básica (para o trabalhador), não poderíamos ampliar essa compreensão à Educação Superior? Vejamos duas passagens de um texto, relativamente recente do prof. Saviani (2007), sobre sua compreensão do Ensino Médio e sobre a Educação Superior:

O ensino médio envolverá, pois, o recurso às oficinas nas quais os alunos manipulam os processos práticos básicos da produção; mas não se trata de reproduzir na escola a especialização que ocorre no processo produtivo. $\mathrm{O}$ horizonte que deve nortear a organização do ensino médio é o de propiciar aos alunos o domínio dos fundamentos das técnicas diversificadas utilizadas na produção, e não o mero adestramento em técnicas produtivas. Não a formação de técnicos especializados, mas de politécnicos. (...) [Sobre a Educação Superior] [...] Terminada a formação comum propiciada pela educação básica, os jovens têm diante de si dois caminhos: a vinculação permanente ao processo produtivo, por meio da ocupação profissional, ou a especialização universitária. Ora, em lugar de abandonar o desenvolvimento cultural dos trabalhadores a um processo difuso, trata-se de organizá-lo. [...] Com isso, além de propiciar o clima estimulante imprescindível à continuidade do desenvolvimento cultural e da atividade intelectual dos trabalhadores, tal mecanismo funciona como um espaço de articulação entre os trabalhadores e os estudantes universitários, criando a atmosfera indispensável para vincular de forma indissociável o trabalho intelectual e o trabalho material (SAVIANI, 2007, p. 161).

Certamente que Saviani não tem o mesmo foco que temos aqui, embora também esteja refletindo a "escola para o trabalhador". Em seu texto, revê os conceitos de politecnia, educação tecnológica, etc., procurando problematizar o que está mais pertinente à tradição marxista. Mas, olhando as passagens dele, não nos parece que a proposta dos IF é a que melhor pode desenvolver uma formação do Ensino Médio como a que foi descrita acima, e ainda associá-la a uma proposta de Educação Superior que não se distancie dos trabalhadores? Cada vez mais, vamos construindo o entendimento que buscamos um "Instituto Unitário" que se oponha aos vários dualismos da educação, que se oponha à divisão entre formação técnica e propedêutica, entre a escola para trabalhadores e a escola dos mais abastados, entre ciências naturais e ciências humanas, entre periferia e centro. Nos parece que os IF tem potencial para isso. 


\subsection{Retomando as críticas à verticalização...}

Parece que a desconfiança sobre o projeto dos IF persiste e de tal forma que talvez fiquemos com a dúvida: é um projeto que pode não avançar por conta de um "mal de origem" (predisposto a precarizar a EB e a ES, por conta do próprio convívio,) ou por conta dos agentes envolvidos não o implementarem? Até em relação aos itens que em tese são mais favoráveis aos IF, são desqualificados por alguns autores, como a enorme capilaridade que possuem em relação às universidades. Rocha e Léda (2013), por exemplo, criticam a interiorização dos campi dos IF que não considera

(...) ausência de uma formação adequada nessas localidades, os professores são provenientes da capital, ou até mesmo das capitais de outros estados. Além das dificuldades em se dedicar à família, que na maioria dos casos permanece na cidade de origem, muitas vezes esses professores dividem a sua carga horária com atividades nos campi do interior e em instituições na própria capital, o que gera uma série de custos, não só financeiros, mas de energia e de tempo.

Para tentar atender às expectativas desses profissionais, surgem vários concursos de remoção, que possibilitam a realocação desses servidores em municípios mais próximos de suas cidades de origem, gerando expectativas nos novos professores e fragmentação das equipes dos campi, visto a incerteza de contar com o profissional no futuro. Outro dado relevante é que o grande número de concursos e contratações, nos campi antigos, ocasionam cisões nos departamentos entre os antigos e os novos professores, que divergem, muitas vezes, de opinião em relação a questões relevantes para a instituição (ROCHA e LÉDA, 2013, p. 5).

Rufino Neto (2012) reforça que são tantos os desafios dos IF, os quais começam pela escassez de recursos financeiros, humanos e de infraestrutura, considerando a expansão pretendida pelo governo federal no curto tempo sem o amadurecimento da compreensão das propostas presentes nos documentos legais, que declara seu receio de que

Sem uma reflexão aprofundada do papel dos IFET's na sociedade brasileira, os campi isoladamente correm o risco de se limitarem ao imediatismo das "demandas de mercado". Se isto ocorrer, os IFET's podem ser obrigados pelas circunstâncias a desenvolver pseudo (ensino/pesquisa/extensão) apenas para dar respostas superficiais às diretrizes oficiais, marginalizando-se à falta de identidade própria (nem escolas técnicas, nem ciência e tecnologia, nem universidades). Enfim, os institutos precisam criar sua identidade de ensino, pesquisa 
e extensão, porém, não podemos aceitar que esta identidade signifique ensino, pesquisa e extensão a menor custo do que nas universidades e que estas atividades acadêmicas se tornem reféns das demandas de mercado (RUFINO NETO, 2012, p. 53).

Para nós, tantos as críticas de origem, quanto as que prosseguem acompanhando o desenvolvimento dos IF são imprescindíveis, pois somente com elas é possível dar contornos mais favoráveis à escola que realmente queremos para os trabalhadores. A questão, conforme exposta anteriormente, é: as críticas deverão ser utilizadas para refutar o projeto dos IF ou aperfeiçoá-lo? Considerando que não desejamos ser reformistas (porque reformar não é o projeto político para educação em que nos filiamos), a nossa reflexão alcança que abandonar por completo o projeto dos IF será mais prejudicial aos interesses da classe trabalhadora do que aos interesses dos "homens de negócio" (principalmente os que estão lutando pela ampliação do "mercado da educação" ou no máximo compreendem a "educação como sendo capital humano"). Diante das disputas que há na sociedade brasileira em torno da educação, a expansão dos IF não seria mais pertinente à classe trabalhadora do que a ampliação do ensino superior privado associado às formações profissionais aligeiradas que estão no mercado da educação (ou mesmo em relação às formações ofertadas pelo “Sistema S”)?

\section{Horizontalidade na Verticalização e os desafios que permanecem: nossas considerações finais}

Apesar da linha de argumentação que desenvolvemos até aqui, vale uma ressalva: não será qualquer verticalização que valerá a pena. Os vícios na implementação da verticalização já a comprometeu muito, mas o que poderá determinar realmente seu fracasso será manter-se ditatorial, posta de cima para baixo, sem

\footnotetext{
$7 \quad$ "Homens de negócios" aqui no seu sentido assumidamente ideologizado, como sendo aqueles que possuem estritamente interesse de mercado e, no caso, especialmente os que desejam mercantilizar a “educação". Vale uma citação de Frigotto (1995) que circunscreve até onde podem chegar: "Os novos conceitos abundantemente utilizados pelos homens de negócio e seus assessores - globalização, integração, flexibilidade, competitividade, qualidade total, participação, pedagogia da qualidade e defesa da educação geral, formação polivalente e "valorização do trabalhador" - são uma imposição das novas formas de sociabilidade capitalista tanto para estabelecer um novo padrão de acumulação quanto para definir as formas concretas de integração dentro da nova reorganização da economia mundial." (p. 144, grifo nosso).
} 
democratizar sua gestão, sem ouvir docentes, discentes e servidores técnicosadministrativos. A verticalização para obter sucesso precisará observar especificidades, identidades, identificações, etc. Numa dissertação de mestrado de 2016, por exemplo, que estudou o "trabalho docente na verticalização (...)" foi possível observar que:

\begin{abstract}
A fragmentação do trabalho docente cria empecilhos para a realização da integração da educação básica à superior, ratifica o individualismo e desencoraja o movimento associativo entre os professores. Ao mesmo tempo, a fragmentação é também resultado da intensificação do trabalho docente, uma vez que a sobrecarga ecoa no sentido do trabalho e no estabelecimento da identidade do professor enquanto uma coletividade (OLIVEIRA, 2016, p. 139).
\end{abstract}

Para nós que vivemos o dia-a-dia de um Instituto Federal, tendo conhecimento dos debates que envolvem docentes, demais servidores e discentes, sabemos, por exemplo, como é temerário desrespeitar certos engajamentos, identificações, filiações, agrupamentos que foram conquistados pelas pessoas ou que as envolveram das mais variadas formas. É necessário respeitar certa "horizontalidade dentro da verticalização". Ainda com esse exemplo do trabalho docente, é preciso entender que alguns docentes trabalham e lutam mais por um curso do que outros, por um nível, por um setor, por uma pesquisa, por uma disciplina e que não quererão trabalhar em vários níveis ou em vários cursos ou em vários lugares. E que isso também não é producente aos próprios cursos, pois não é bom que seus docentes estejam em vários outros e não criem laços ou identidade.

Por fim, mais importante do que chegar aqui e dizer que confirmamos nossa hipótese - de que mesmo quando os gestores "acreditam" na verticalização não a implementam ou não participam de ações (da macro ou micropolítica) no sentido de fortalecê-la - é alcançar uma reflexão que mostrou: 1) haver um processo de idas e vindas na educação profissional federal, que aparecem com políticas de expansão ousadas, mas geralmente idiossincráticas; 2) haver nenhuma adesão ou uma adesão pouco entusiasmada com o que vem de cima, no caso em relação à verticalização; 3) haver uma desconfiança de origem que tem muitos elementos que permanecem em relação ao convívio entre a Educação Básica e a Educação Superior; 4) que, apesar de tudo isso, pode ser uma oportunidade e que deveríamos mais aperfeiçoá-la que abandoná-la; 5) creditar mais na verticalização (em vez de “acreditar”) e buscar 
encaminhamentos para sua materialização pode ser sim uma possibilidade favorável à classe trabalhadora e não o contrário.

Sem um progressivo e consciente intercâmbio com os processos de educação abrangentes como "a nossa própria vida", a educação formal não pode realizar as suas muito necessárias aspirações emancipadoras. $\mathrm{Se}$, entretanto, os elementos progressistas da educação formal forem bem-sucedidos (...) poderão dar uma contribuição vital para romper a lógica do capital, não só no seu próprio e mais limitado domínio como também na sociedade como um todo. (MÉSZÁROS, 2005, p. 27).

Sabemos que os IF estão muito longe da "escola dos trabalhadores" necessária e ainda fazem parte da educação formal que talvez mais reproduza do que liberte, mas que experiência concreta pode estar mais próxima das "aspirações emancipadoras" (conforme Mészáros) ou qual podemos fazer aproximar?

\section{Referências}

BOAVENTURA, G. A. R. Tensões e perspectivas da rede federal no campo da educação profissional e tecnológica: um estudo do IF Goiano nos Campi Ceres e Rio Verde-Goiás. Tese de doutorado em Educação. PUC Goiás. 210 f. 2016.

BOMFIM, A. M. O Convívio da Educação Superior com a Educação Básica nos Institutos Federais: perderemos essa oportunidade. In ANJOS, M. B.; RÔÇAS, G. (orgs.). As políticas públicas e o papel social dos Institutos Federais de Educação, Ciência e Tecnologia. Natal-RN: Editora IFRN.

BRASIL. Lei $\mathrm{n}^{\circ}$ 11.892. Presidência da República. Casa Civil. Institui a Rede Federal de Educação Profissional, Científica e Tecnológica, cria os Institutos Federais de Educação, Ciência e Tecnologia, e dá outras providências. Disponível em: <https://www.planalto.gov.br/ccivil_03/_ato2007-2010/2008/lei/111892.htm>. 2008.

CAMPELlO, A. M. "Cefetização" das Escolas Técnicas Federais-Projetos em disputa, nos anos 1970 e nos anos 1990. Educação e Tecnologia, v. 12, n. 1, p. 1-10, 2007.

FERNANDES, M. R. S. O processo de verticalização da educação profissional e tecnológica e suas implicações na qualidade do trabalho dos docentes do Câmpus São Vicente do Sul do Instituto Federal Farroupilha. Dissertação de mestrado em Educação Agrícola. Universidade Federal Rural do Rio de Janeiro. 103 f. 2013.

FERRETTI, C. J. Problemas institucionais e pedagógicos na implantação da reforma curricular da educação profissional e técnica de nível médio no IFSP. Educação e Sociedade, v. 32, n. 116, p. 789-806, 2011. 
FRIGOTTO, G. A Produtividade da Escola Improdutiva. 4. ed. São Paulo: Cortez, 1993.

FRIGOTTO, G. A educação e a crise do capitalismo real. São Paulo: Cortez, 1995.

FRIGOTTO, G.; CIAVATTA, M.; RAMOS, M. A política de educação profissional no governo lula: um percurso histórico controvertido. Educação e Sociedade. v. 26, n. 92, p. 1087-1113, Especial.

Disponível <http://www.scielo.br/pdf/es/v26n92/v26n92a17.pdf>. Acesso em: 12 fev. 2017.

RUFINO NETO, J. A missão institucional do campus Crato do IFCE: percepção da comunidade escolar sobre os avanços e desafios para desenvolver o ensino, a pesquisa e a extensão em um novo projeto de sociedade. Dissertação de mestrado em educação agrícola. Universidade Federal Rural do Rio de Janeiro. 65f. 2012.

LOMBARDI, J. C. Educação e ensino na obra de Marx e Engels. São Paulo, Alínea, 2011.

MACHADO, L. R. De S. Politecnia, Escola Unitária e Trabalho. São Paulo: Cortez: Autores Associados, 1989.

MÉSZÁROS, I. A educação para além do capital. São Paulo: Boitempo, 2005.

OLIVEIRA, B. C. O trabalho docente na verticalização do Instituto Federal de Brasília. Dissertação de mestrado em Educação. Universidade de Brasília. 170 f. 2016.

PACHECO, E. M. (Org.). Institutos Federais: uma revolução na educação profissional e tecnológica. Fundação Santilana. São Paulo: Ed. Moderna, 2011.

PADILHA, R. F. S. J; FILHO, D. L. L. A oferta de educação profissional verticalizada nos Institutos Federais de Educação, Ciência e Tecnologia, o que há de novo? Anais da Reunião Científica Regional da Anpes, Curitiba, 15 p. 2016.

ROCHA, L. F. S; LÉDA, D. B. Desafios da expansão da educação profissional e suas repercussões no trabalho docente: o caso do IFMA. Anais do VI Jornada Internacional de políticas públicas. UFMA, São Luiz do Maranhão, p. 1-10, 2013.

SAVIANI, D. Trabalho e Educação: fundamentos ontológicos e históricos. Revista Brasileira de Educação, v. 12, n. 34, p. 152-180, 2007. Disponível em: <http://www.scielo.br/pdf/rbedu/v12n34/a12v1234.pdf>. Acesso em: maio de 2017. 